\title{
Erratum to \\ Chemical Composition of Polymer Surfaces Imaged by Atomic Force Microscopy and Complementary Approaches
}

G. Julius Vancso $(-) \cdot$ Henrik Hillborg $\cdot$ Holger Schönherr

$\mathrm{MESA}^{+}$Institute for Nanotechnology and Faculty of Science and Technology,

Department of Materials Science and Technology of Polymers, University of Twente,

P.O. Box 217, 7500 AE Enschede, The Netherlands

g.j.vancso@tnw.utwente.nl

Unfortunately, the editor of this article Hans-Henning Kausch was published as author in the XML-version. 